\title{
FLOREAL RECABARREN ROJAS (1927-2020)
}

\author{
José Antonio González Pizarro*
}

Juan Floreal Recabarren Rojas fue profesor e historiador de Antofagasta. Nacido en los estertores de la industria salitrera, el 21 de abril de 1927, falleció en momentos de otro destino en nuestra historia, la Constitución de 1980, el 16 de junio de 2020.

Conoció ampliamente las calles y lugares más emblemáticos de su urbe. Nos confesaba en el año 2018, en varias entrevistas, que le tocó vivir los años difíciles de Antofagasta. Una urbe olvidada por el Estado. Sin esperanzas, con una crisis que golpeaba los hogares. Educado en el Liceo de Hombres marchó a Santiago a estudiar historia en el Instituto Pedagógico de la Universidad de Chile. Ahí tuvo como profesores a Ricardo Donoso Novoa, Guillermo Feliú Cruz, Hernán Ramírez Necochea, etc. Su Memoria de Prueba para optar al título de Profesor de Historia, Geografía y Educación Cívica, de 1954, se tituló Historia del proletariado de Tarapacá y Antofagasta (1884-1913), con máxima calificación. La aproximación ya delató su amor por el terruño. Escribe en la introducción:

Estas páginas no pretenden casi nada, desean ser un grano de arena para el acopio general de la Historia Social de Chile.

Hemos escogido la zona norte... La consecuencia de ello fue el haber engendrado al primer proletariado chileno, que después de un proceso de toma de conciencia de su importancia como clase social, irrumpe vigorizado y combativo a la vida nacional, en los albores del siglo XX (Recabarren, 1954: 9).

En Antofagasta fue profesor en el Liceo de Hombres, bajo la rectoría de Mario Bahamonde, el notable escritor taltalino de cuentos y novelas, y se vinculó con las actividades políticas de la Falange Nacional, posteriormente Partido Demócrata Cristiano, donde le cupo en la década de 1960-70, desenvolverse como alcalde de la ciudad y diputado. Aquellos años, le quitaron el tiempo para dedicarse a la historia local y regional.
Incorporado como docente en el Departamento de Ciencias Sociales, de la Universidad de Chile, de Antofagasta, desarrolló con sus colegas Juan Panadés Vargas y Antonio Obilinovic Arrate, las primeras incursiones en la historia local. El primer fruto fue Antofagasta, una historia en imágenes, publicada por la Editorial Universitaria en 1979. Los autores expresaban:

Nos guía un propósito didáctico, un afán
de investigar nuestra historia regional, un
deseo de enseñar a todos quienes quieran
aprender de este Norte, grande en riqueza y
en espíritu. Queremos escudriñar cada rincón
de nuestra historia nortina, rescatarla de un
pasado casi olvidado. En la medida que lo
logremos, estaremos también construyendo
la historia regional (Panadés et al. 1979: 8).

En 1983, los tres académicos volvieron a incursionar en otro trozo de la historia local, Coloso, una aventura histórica. Fue la primera obra editada bajo la nueva realidad universitaria: la Universidad de Antofagasta. Se trataba de rescatar un puerto al sur de Antofagasta, vinculado a las actividades de los industriales salitreros Baltazar Domínguez Lasierra y Matías Granja Nagel, los que, después de ser autorizada la habilitación como puerto, en 1902, van a unir Coloso con el cantón de Aguas Blancas. Era un jirón de historia que, a una distancia de 15 kilómetros de Antofagasta, había tejido leyendas y realidades, hasta su desarme a principios de la década de 1930.

Recrear Coloso fue acudir a una narración que de nuevo unió el destino de la costa del desierto de Atacama con la pampa salitrera. En sus páginas se recorre la habilitación del pueblo, su escuela, las viviendas, los decretos. Faltó la vitalidad de lo cotidiano, aun cuando pudieron incorporar los datos de un par de entrevistas. Se destacó en el volumen el cuidado por rescatar la iconografía de la época -muy propia, a decir verdad de Juan Panadés- y un estilo sencillo donde se describió el

\footnotetext{
Universidad Católica del Norte. Escuela de Derecho- Antofagasta. Facultad de Ciencias Jurídicas. Chile. Correo electrónico: jagonzal@ucn.cl
} 
nacimiento y desaparición de Coloso. Y el sentido de este esfuerzo intelectual:

La historia de la región es una historia trunca... una historia, en sentido figurado, se corta. Pensamos que el norte necesita un desarrollo que afiance la presencia humana en forma permanente. Es preciso que el Norte encuentre su verdadero destino, para que no todo sea "una aventura" como lo fue Coloso (Recabarren et al. 1989: 7-8).

Alejado de las aulas universitarias, Floreal Recabarren retomó la historiografía, una vez retornada la democracia en 1990, y después de haber ejercido la alcaldía, por segunda vez, entre 1990-1992, y ser concejal hasta 1996.

Se desempeñó como profesor en la Universidad José Santos Ossa, animando con Héctor Ardiles una secuencia de la historia de Antofagasta mediante fascículos que fueron apareciendo en El Mercurio de Antofagasta.

El entusiasmo por la historia lo llevó a ser uno de los fundadores del Centro de Investigación Histórico Cultural Isaac Arce Ramírez (C.I.I.A.R), vinculado con el Museo Regional de Antofagasta. Animó sus jornadas de conferencias e impulsó el rescate de las Actas Municipales y la prensa local desde su colaboración en el Museo Regional.

En el 2002 dio a conocer su libro Episodios de la vida regional, editado por la Corporación Pro Antofagasta y la Universidad Católica del Norte.

Por medio de una breve narración, Recabarren hizo desfilar variados acontecimientos como lugares y personalidades que jalonaron la historia regional en los siglos XIX y XX, sea en la costa, con relatos de Cobija, Taltal, Tocopilla, o también del interior, principalmente de los denominados "pueblos fantasmas", Yungay y también Pampa
Unión. No descuidó nombres señeros, comenzando por Isaac Arce, Matías Rojas, Maximiliano Poblete, Andrónico Abaroa, etc. No se le escapó aquellos hitos que llevaron temor y miedo a la ciudadanía, el maremoto de 1922, la peste bubónica en Tocopilla de 1912, el aluvión en Tocopilla de 1940, entre otros, un recorrido por los templos católicos más señeros y patrimonio de la arquitectura citadina, el Corazón de María, la Iglesia San Francisco, o bien episodios que forjaron la identidad y el orgullo de ser antofagastinos, las Ruinas de Huanchaca, la Quinta Casale, la Casa Giménez que se acomodan con el Movimiento Constitucionalista o la época en que Antofagasta fue el "Hollywood chileno", en la década de 1920; la visita de Balmaceda, o la tres visitas de Gabriela Mistral. En este friso, acudió a los testimonios contados por Radomiro Tomic o Mario Bahamonde, este último testigo de la tercera visita de Gabriela Mistral a la ciudad, "me extraña que los maestros no me escriban nunca", le confidenció la Premio Nobel al escritor taltalino (Recabarren, 2002, 189).

Su última contribución fue en el 2017, cuando junto con Pamela Ramírez hicieron una revisita a la historia de Coloso. El volumen Coloso ayer y hoy fue publicado por la Corporación Pro Antofagasta. Su contribución fue de otra factura. Con pluma ágil y sobria fue pasando revista a los pasajes más importantes del pasado de Coloso, mediante gráficos, fotografías, donde la articulación del texto con la iconografía variada, se tradujo en un libro que tejió el pasado con la actualidad de Coloso.

Aun cuando ya se encontraba muy delicado, no cejó de escribir en las páginas de la prensa local, tocando temas que enlazaban el pretérito vivencial en la urbe con las meditaciones acerca del acontecer regional y nacional. Se despidió enseñando que la historia es maestra de vida.

\section{Referencias Citadas}

Panadés, J., Recabarren, F., y Obilinovic, A.

1979 Antofagasta: Una Historia en Imágenes. Editorial Universitaria. Santiago.

Recabarren Rojas, F.

1954 Historia del Proletariado de Tarapacá y Antofagasta (1884-1913). Memoria de Prueba para optar al título de Profesor de Historia, Geografía y Educación Cívica. Instituto Pedagógico. Universidad de Chile. Santiago. Inédita.
Recabarren Rojas, J.F.

2002 Episodios de la Vida Regional. Corporación Pro Antofagasta- Universidad Católica del Norte. Antofagasta Recabarren Rojas, F., Obilinovic A.A. y Panadés Vargas, J. 1989 [1983] Coloso, Una Aventura Histórica. Universidad de Antofagasta. Antofagasta.

Recabarren, F. y Ramírez, P. 2017 Coloso Ayer y Hoy. Corporación Pro Antofagasta. Antofagasta. 